\title{
A Dual CuH- and Pd-Catalyzed Stereoselective Synthesis of Highly Sub- stituted 1,3-Dienes
}

\author{
Chuan-Jin Hou ${ }^{\ddagger}$, Alexander W. Schuppe $\$$, James Levi Knippel, Anton Z. Ni, and Stephen L. Buchwald*
}

Department of Chemistry, Massachusetts Institute of Technology, Cambridge, Massachusetts 02139, United States

Supporting Information Placeholder

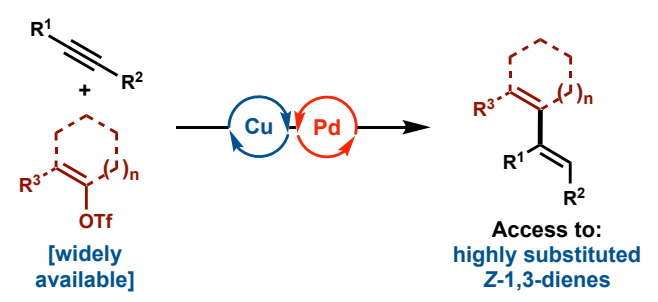

ABSTRACT: Conjugated dienes are versatile building blocks and prevalent substructures in synthetic chemistry. Herein, we report a method
for the stereoselective hydroalkenylation of alkynes, utilizing readily available enol triflates. We leveraged an in situ generated and geometrically
pure vinyl- $\mathrm{Cu}(\mathrm{I})$ species to form the $Z, Z$ - or $Z, E-1,3$-dienes in excellent stereoselectivity and yield. This approach allowed for the synthesis of
highly substituted $Z$-dienes, including pentasubstituted 1,3-dienes, which are difficult to prepare by existing approaches.

Conjugated dienes are a prevalent structural element present in numerous biologically active small molecules ${ }^{1-5}$ and constitute a major feedstock for industrial polymer production. ${ }^{6-7}$ Owing to their unique chemical reactivity, 1,3-dienes are versatile building blocks with the potential to form new $\mathrm{C}-\mathrm{C}$ and $\mathrm{C}-$ heteroatom bonds at all four encompassing carbons. ${ }^{8}$ The utility of conjugated dienes has been demonstrated in a variety of critical synthetic processes, including: cycloadditions, ${ }^{9-10}$ hydrofunctionalizations, ${ }^{11-13}$ and difunctionalizations. ${ }^{14-16}$ The stereochemical outcome of these methods is typically influenced by the olefin geometry of the 1,3-diene substrate. ${ }^{10,14,15}$ Accordingly, methods to access substituted 1,3-dienes in a stereoselective manner are paramount for their use in fine chemical synthesis. ${ }^{8,16}$ While various methods exist for the synthesis of $E, E$ dienes, ${ }^{16-18}$ a general, highly stereoselective process to produce $Z$ dienes is desirable.

Due to the utility of 1,3-dienes in organic synthesis, a variety of strategies to access these compounds have been developed. ${ }^{8,16}$ Olefination of carbonyl compounds with stoichiometric allyl nucleophiles has been widely employed in the synthesis of conjugated dienes, ${ }^{19-26}$ however, the products are generally obtained as inseparable E/Z-mixtures (Figure 1A). ${ }^{26-27}$ Although considerable advances have been made towards stereoselective olefination of carbonyl substrates, most methods to access 1,3-dienes result in the E,E-isomer. ${ }^{18,24,26,28}$ To avoid the formation of isomeric product mixtures, transition-metal catalyzed cross-coupling utilizing preformed organometallic reagents and vinyl (pseudo)halides has emerged as a practical route to stereoselectively synthesize dienes (Figure 1B). ${ }^{29-}$

A. Traditional olefination strategies result in mixtures of olefin isomers

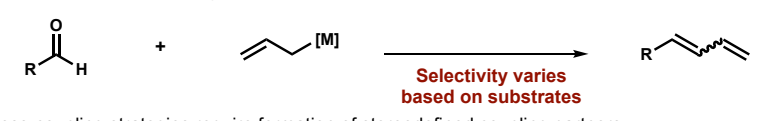

B. Cross-coupling strategies require formation of stereodefined coupling partners
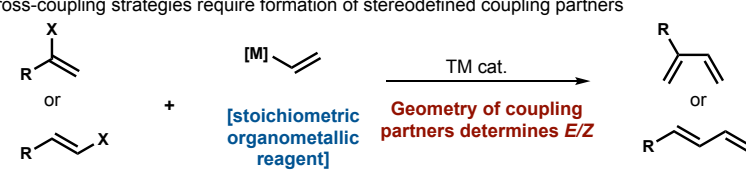

C. Dual $\mathrm{CuH}$ - and Pd-catalyzed hydroalkenylation of olefins and alkynes
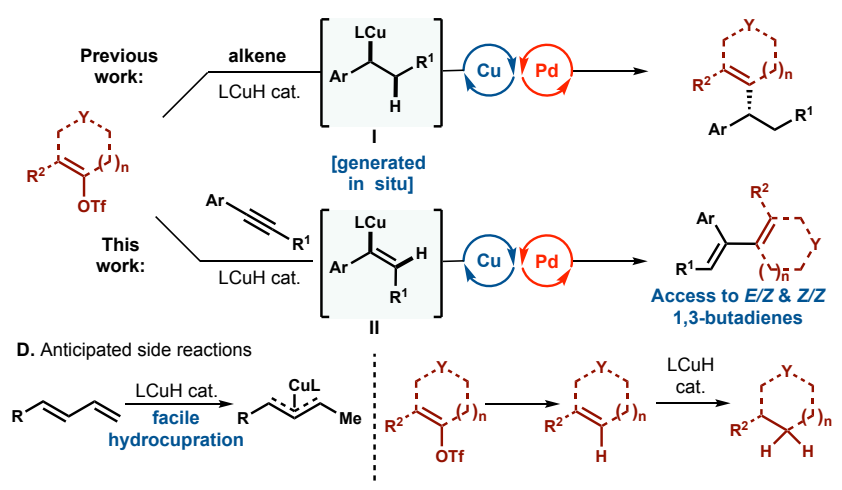

Figure 1: (A) Olefination employing stoichiometric allylation reagents. (B) Cross-coupling of vinyl-metal species with stereodefined coupling partners. (C) Proposed dual $\mathrm{CuH}$ - and Pd-catalyzed alkyne hydroalkenylation. (D) Potential undesired reactions. 
by the stereochemistry of the coupling partners. Complementary approaches to prepare 1,3-dienes, including $\mathrm{C}-\mathrm{H}$ activation of olefin starting materials, ${ }^{35-36}$ rearrangements of allenes or alkynes, ${ }^{37}$ and ene-yne metathesis of acyclic precursors, ${ }^{38-39}$ have also been developed. $^{40-41}$

Our group and others have demonstrated the potential of $\mathrm{CuH}$ catalyzed hydrofunctionalization reactions to enable unsaturated substrates to serve as surrogates for preformed organometallic reagents. ${ }^{42-43}$ Hydrocupration of an olefinic precursor results in a catalytically generated $\mathrm{Cu}(\mathrm{I})$ species $(\mathbf{I})$ that can engage in bond-forming reactions with a range of electrophiles, including carbonyls, ${ }^{44}$ heterocycles, ${ }^{45-46}$ and LPd(II)-complexes. ${ }^{4-50}$ However, the equivalent transformations employing alkyne pronucleophiles have been underexplored. ${ }^{51-60}$ Recently, we developed a dual $\mathrm{CuH}$ - and Pd-catalyzed hydroalkenylation of olefins (Figure 1C), employing widely available enol sulfonates to synthesize highly substituted $\alpha$-chiral olefins. ${ }^{50} \mathrm{We}$ reasoned that an analogous approach to generate the otherwise elusive $Z, E$ - and $Z, Z$-1,3-dienes could be realized by exploiting the syn-selective hydrocupration of alkynes and the rapid transmetalation of a vinyl-Cu(I) species (II) with an LPd(II)alkenyl complex. ${ }^{60} \mathrm{We}$ anticipated several specific challenges for the dual-catalytic alkyne hydroalkenylation (Figure 1D). It was evident that the 1,3-diene products are competent substrates for hydrofunctionalization reactions. Subsequent reduction, ${ }^{42-43}$ isomerization, or oligomerization reactions of the conjugated diene product were also conceivable. Hydrolysis or reduction of the enol triflate to generate the corresponding olefin are also possible. We reasoned that tuning the rates of the two catalytic cycles (e.g., hydrocupration, oxidative addition, transmetalation) would be crucial to suppress off-cycle reactivity and enable construction of the $\mathrm{C}-\mathrm{C}$ bond at the resulting diene 2-position. ${ }^{50}$

We focused on developing a set of dual-catalytic conditions for the stereoselective alkyne hydroalkenylation, using 1-phenyl-1hexyne (1a) as a model substrate and 1-cyclohexenyl trifluoromethanesulfonate (2a) as the alkenyl coupling partner (Table 1). ${ }^{61}$ Utilizing our previously described reaction conditions for olefin hy-

Table 1. Optimization of the Stereoselective Hydroalkenylation of Alkynes $^{a}$

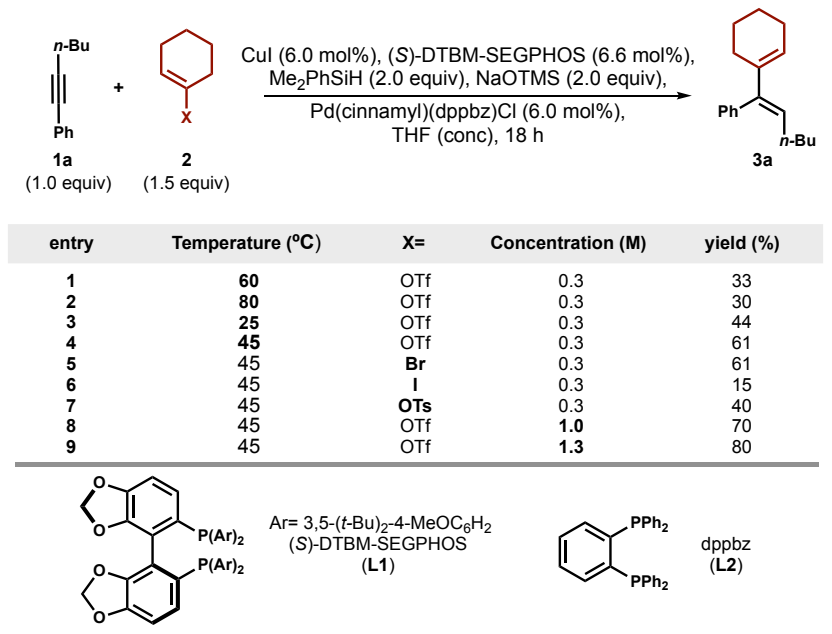

${ }^{a}$ Reaction conditions: $0.2 \mathrm{mmol}$ alkyne (1a), alkenyl coupling partner (2) ( $0.3 \mathrm{mmol}, 1.5$ equiv), yields were determined by ${ }^{1} \mathrm{H}$ NMR spectroscopy of the crude reaction mixtures, using 1,3,5-trimethoxybenzene as an internal standard.

droalkenylation, ${ }^{50}$ we observed the $Z$-diene (3a) in moderate yield
Scheme 1. Substrate scope of alkyne coupling partners ${ }^{a}$

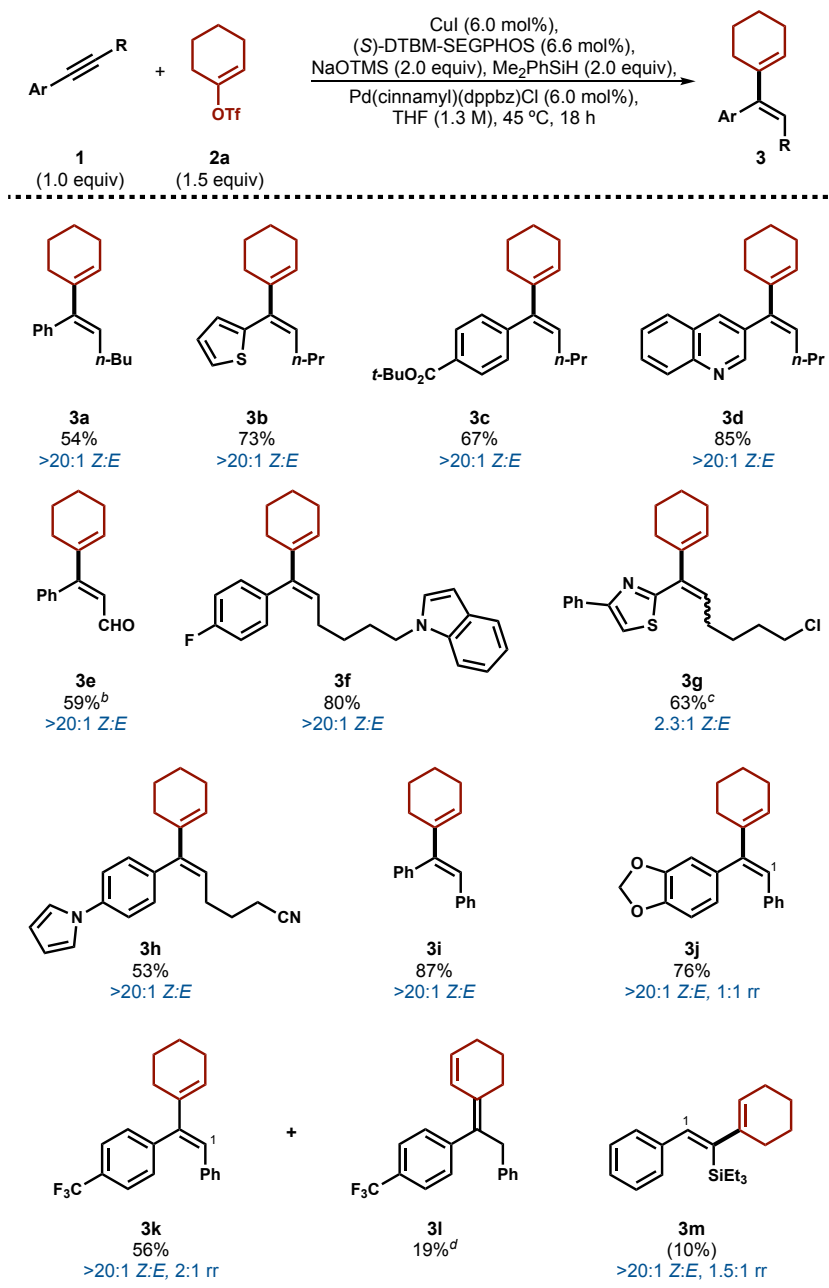

${ }^{a}$ All yields represent the average of at least two isolated yields of reactions conducted with $0.5 \mathrm{mmol}$ of alkyne (1); the corresponding enol triflate was used unless otherwise noted. The yields in parentheses were determined by ${ }^{1} \mathrm{H}$ NMR spectroscopy of the crude reaction mixtures using 1,1,2,2-tetrachloroethane as an internal standard. The position of the minor regioisomer is denoted by a $1 .{ }^{b}$ The corresponding propargylic diethyl acetal was utilized ${ }^{~}$ Isolated as a 2.3:1 Z:E mixture ${ }^{d}$ Isolated separately from $3 \mathbf{k}$.

(entry 1, 33\% yield, as determined by ${ }^{1} \mathrm{H}$ NMR). Contrary to our olefin hydroalkenylation process, which was ineffective at room temperature ${ }^{50}$ we found that conducting the alkyne hydroalkenylation at room temperature resulted in moderate yield of $\mathbf{3 a}$ (entry 3 ). As hydrocupration of a vinyl arene and $\mathbf{1 a}$ readily occurs at room temperature, this dichotomy may arise from the more facile transmetalation of a vinyl- $\mathrm{Cu}(\mathrm{I})$ species (II) to a $\mathrm{LPd}(\mathrm{II})$ complex, relative to I. ${ }^{60}$ However, $45^{\circ} \mathrm{C}$ was identified as the optimal temperature for the formation of the diene product (entries 1-4). Although similar results were seen with a vinyl bromide (2b), as compared with $\mathbf{2 a}$, the use of the corresponding vinyl iodide $(\mathbf{2 c})$ or enol tosylate $(\mathbf{2 d})$ were less effective (entries 5-7), and resulted primarily in reduction of the alkenyl coupling partner. Increasing the reaction concentration resulted in an improved yield of $\mathbf{3 a}$ (entries 8-9). Examination of alternative solvents, ancillary ligands for $\mathrm{Cu}$ or $\mathrm{Pd}$, and $\mathrm{Cu}$ salts did not improve the yield of 3a (See Table SI1-2 in Supporting Information for details). When the reaction was run in the absence of a Pd- or Cu- 
Scheme 2. Substrate scope of stereoselective hydroalkenylation of alkynes with various enol triflate coupling partners ${ }^{a}$

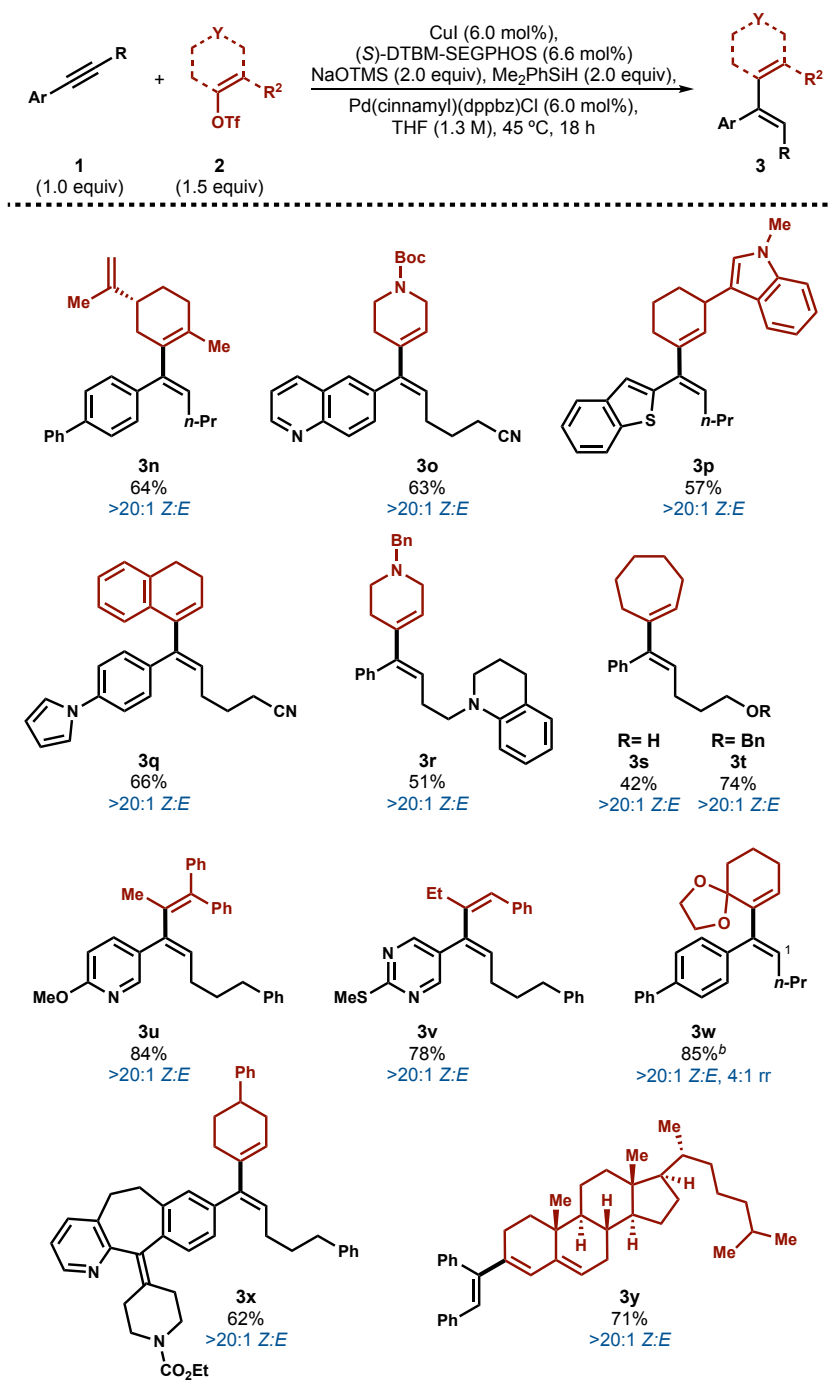

${ }^{a}$ All yields represent the average of at least two isolated yields with 0.5 mmol of alkyne (1); the corresponding enol triflate was used unless otherwise noted. The position of the minor regioisomer is denoted by a 1 . ${ }^{b}$ The corresponding vinyl bromide was used.

catalyst, trace or no product was observed, respectively (see Table SI3).

With our optimized protocol for the synthesis of 1,3-dienes, we sought to explore the range of alkynes that could be utilized in this transformation (Scheme 1). When 2a was employed with 1-phenyl1-hexyne or diphenyl acetylene the corresponding dienes (3a, 3i) were accessed in good yield with excellent $Z$-selectivity (>20:1 Z:E). $A$ variety of heteroaryl containing $Z$-dienes could be prepared in excellent selectivity, including a thiophene (3b), quinoline (3d), pyrrole $(\mathbf{3 h})$, and indole (3f). A thiazole containing diene $(\mathbf{3 g})$ was the only product where the $E$-isomer was detected (2.3:1 Z:E). An ester (3c) was tolerated under the reaction conditions, however, a diethyl acetal hydrolyzed to the corresponding aldehyde (3e) upon isolation. When unsymmetrical diaryl alkynes were subjected to the reaction conditions, regioisomeric mixtures of diene products were observed (3j, 3k). An electron-deficient 1-aryl alkyne resulted in the expected 1,3-diene (3k) in conjunction with isomer 31 . This isomerized product may arise from a subsequent hydrocupration, to form an allyl-Cu(I) species, followed by $\beta$-hydride elimination. A series of 1-silyl substituted acetylenes, including -TMS and -TIPS, did not result in the diene adduct (3), although a -TES substituted butadiene $(\mathbf{3 m})$ was formed as a minor product, favoring hydride addition $\beta$ to silicon. ${ }^{62}$ This regiochemical reversal is likely due to stereoelectronic effects exerted by the nearby silicon atom, increasing cationic character at the $\beta$-position. ${ }^{63}$ When a 1,2 -dialkyl alkyne, 4-octyne, was employed as a substrate in the alkyne hydroalkenylation process, only reduction of $\mathbf{2} \mathbf{a}$ was observed (see Scheme SI1). This result can possibly be attributed to the more challenging hydrocupration of 1,2-dialkyl alkynes, relative to 1 -aryl-2-alkyl alkynes. ${ }^{51}$

The scope with respect to the enol triflate coupling partner was evaluated with a selection of differentially substituted alkynes, as depicted in Scheme 2. A range of alkenyl groups, including benzofused $(\mathbf{3 q})$, heterocyclic $(\mathbf{3} \mathbf{p}, \mathbf{3 r})$, and acyclic $(\mathbf{3 u}, \mathbf{3 v})$, could be appended to the 2-position of the resulting diene. Pentasubstituted 1,3-dienes, such as $\mathbf{3 n}$ and $\mathbf{3 u}$, could be prepared with high yield and selectivity (>20:1 Z:E). A variety of functional groups were tolerated in this process, including nitriles $(\mathbf{3 o}, \mathbf{3 q})$, carbamates $(\mathbf{3 o}, \mathbf{3} \mathbf{x})$, a tertiary amine (3r), and a ketal (3w). While an alkyne with an unprotected alcohol was a suitable substrate (3s), the corresponding benzyl ether resulted in the 1,3-diene product in improved yield (3t), $42 \%$ and $74 \%$ yield, respectively. Despite their increased steric hinderance, acyclic enol triflates enabled access to $3 \mathbf{u}$ and $\mathbf{3 v}$ in excellent yield and selectivity. Heterocycles such as quinoline (3o), pyridine (3u, $\mathbf{3 x})$, pyrimidine $(\mathbf{3 v})$, and indole $(\mathbf{3 p})$ were effectively converted to the corresponding $Z$-dienes. Pharmaceutical derivatives, including a substituted loratadine $(\mathbf{3 x})$ and a steroid-derived triene $(\mathbf{3 y}$,$) are$ readily prepared via this method. A sterically congested $\alpha$-spirocyclic vinyl bromide resulted in a 4:1 regioisomeric mixture of 1,3-diene products $(3 \mathbf{w})$, which is in accordance with our previous observations. ${ }^{50}$ Despite olefins and dienes being suitable substrates for hydrofunctionalization reactions, no subsequent dimerization or oligomerization of the products were observed.

To further demonstrate the utility of this alkyne hydroalkenylation method, we conducted the process on gram scale (eq. 1). Using a commercially available alkyne $(\mathbf{1 b})$ and enol triflate $(\mathbf{2 a})$, diene $\mathbf{3 i}$ could be isolated in $86 \%$ yield and high selectivity $(>20: 1 \mathrm{Z:E})$.
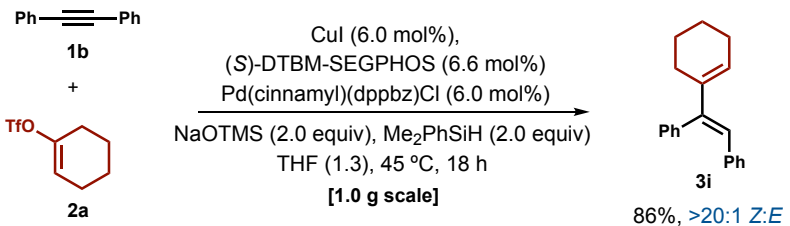

In summary, we have developed a highly stereoselective process to prepare substituted $Z$-1,3-dienes, employing widely available alkynes and enol triflates. Instead of relying on conferring the olefin geometry of the starting material to the product, we leverage an in situ generated and geometrically pure vinyl- $\mathrm{Cu}(\mathrm{I})$ species to access exclusively $Z$-conjugated dienes. The reaction conditions tolerated numerous important functional groups and enabled the synthesis of highly substituted 1,3-dienes, including pentasubstituted dienes, which are difficult to prepare by complementary strategies.

\section{ASSOCIATED CONTENT}

\section{Supporting Information}

The Supporting Information is available free of charge on the ACS Publications website. 
Experimental details and characterization of the products and starting materials. (PDF)

\section{AUTHOR INFORMATION}

\section{Corresponding Author}

Stephen L. Buchwald - Department of Chemistry, Massachusetts Institute of Technology, Cambridge, Massachusetts, 02139, United States; orcid.org/0000-0003-3875-4775; Email: sbuchwal@mit.edu

\section{Authors:}

Chuan-Jin Hou - Department of Chemistry, Massachusetts Institute of Technology, Cambridge, Massachusetts, 02139, United States; School of Light Industry and Chemical Engineering, Dalian Polytechnic University, Dalian 116034, China; orcid.org/0000-0002-18714648

Alexander W. Schuppe- Department of Chemistry, Massachusetts Institute of Technology, Cambridge, Massachusetts, 02139, United States; orcid.org/0000-0001-6002-9110

James Levi Knippel- Department of Chemistry, Massachusetts Institute of Technology, Cambridge, Massachusetts, 02139, United States; orcid.org/0000- 0002-3867-4372.

Anton Z. Ni- Department of Chemistry, Massachusetts Institute of Technology, Cambridge, Massachusetts, 02139, United States; orcid.org/0000-0003-0122-9168

\section{Author Contributions}

${ }^{\ddagger}$ C.-J.H. and A.W.S contributed equally.

\section{Notes}

The authors declare no competing financial interest.

\section{ACKNOWLEDGMENT}

Research reported in this publication was supported by the Arnold and Mabel Beckman Foundation for a postdoctoral fellowship to A.W.S., the National Science Foundation Graduate Research Fellowship Program (1122374) to J.L.K., the National Institutes of Health (R35-GM122483 and Diversity Supplement Fellowship R35-GM122483-03S to J.L.K.), Dalian Polytechnic University (DPU) to C.-J.H., and MIT UROP Direct Funding to A.Z.N. We thank Millipore-Sigma for the generous donation of biarylphosphine ligands. We are grateful to Drs. Veronika Kottisch, Simon Rössler, and Christine Nguyen (MIT) for advice on the preparation of this manuscript.

\section{REFERENCES}

(1) Rychnovsky, S. D. Oxo Polyene Macrolide Antibiotics. Chem. Rev. 1995, 95, 2021-2040.

(2) Thirsk, C.; Whiting, A. Polyene Natural Products. J. Chem. Soc., Perkin Trans. 1 2002, 999-1023.

(3) Zotchev, S. B. Polyene Macrolide Antibiotics and Their Applications in Human Therapy. Curr. Med. Chem. 2003, 10, 211- 223.

(4) Harned, A. M.; Volp, K. A. The Sorbicillinoid Family of Natural Products: Isolation, Biosynthesis, and Synthetic Studies. Nat. Prod. Rep. 201 1, 28, 1790-1810.

(5) Saku, O.; Ishida, H.; Atsumi, E.; Sugimoto, Y.; Kodaira, H.; Kato, Y.; Shirakura, S.; Nakasato, Y. Discovery of Novel 5,5-Diarylpentadienamides as Orally Available Transient Receptor Potential Vanilloid 1 (TRPV1) Antagonists. J. Med. Chem. 2012, 55, 3436-3451.

(6) White, W. C. Butadiene Production Process Overview. Chem.-Biol. Interact. 2007, 166, 10-14.

(7) Thiele, S. K.-H.; Wilson, D. R. Alternate Transition Metal Complex Based Diene Polymerization. J. Macromol. Sci., Part C: Polym. Rev. 2003, 43, 581-628.

(8) De Paolis, M.; Chataigner, I.; Maddaluno, J. Recent Advances in Stereoselective Synthesis of 1,3-Dienes. In Stereoselective Alkene Synthesis; Wang,
J., Ed.; Topics in Current Chemistry; Springer: Berlin, Heidelberg, 2012; pp 87-146.

(9) Nicolaou, K. C.; Snyder, S. A.; Montagnon, T.; Vassilikogiannakis, G. The Diels-Alder Reaction in Total Synthesis. Angew. Chem., Int. Ed. 2002, 41, 1668-1698.

(10) Corey, E. J. Catalytic Enantioselective Diels-Alder Reactions: Methods, Mechanistic Fundamentals, Pathways, and Applications. Angew. Chem., Int. Ed. 2002, 41, 1650-1667.

(11) Perry, G. J. P.; Jia, T.; Procter, D. J. Copper-Catalyzed Functionalization of 1,3-Dienes: Hydrofunctionalization, Borofunctionalization, and Difunctionalization. ACS Catal. 2020, 10, 1485-1499.

(12) Huang, L.; Arndt, M.; Gooßen, K.; Heydt, H.; Gooßen, L. J. Late Transition Metal-Catalyzed Hydroamination and Hydroamidation. Chem. Rev. 2015, 115, 2596-2697.

(13) McNeill, E.; Ritter, T. 1,4-Functionalization of 1,3-Dienes With LowValent Iron Catalysts. Acc. Chem. Res. 2015, 48, 2330-2343.

(14) Xiong, Y.; Sun, Y.; Zhang, G. Recent Advances on Catalytic Asymmetric Difunctionalization of 1,3-Dienes. Tetrahedron Lett. 2018, 59, 347-355.

(15) Wu, X.; Gong, L.-Z. Palladium(0)-Catalyzed Difunctionalization of 1,3-Dienes: From Racemic to Enantioselective. Synthesis 2019, 51, 122-134. (16) Soengas, R. G.; Rodríguez-Solla, H. Modern Synthetic Methods for the Stereoselective Construction of 1,3-Dienes. Molecules 2021, 26, 249.

(17) Wen, Z.-K.; Xu, Y.-H.; Loh, T.-P. Palladium(II)-catalyzed cross-coupling of simple alkenes with acrylates: A direct approach to 1,3-dienes through C-H activation. Chem. Sci. 2013, 4, 4520-4524.

(18) Dong, D.-J.; Li, H.-H.; Tian, S.-K. A highly tunable stereoselective olefination of semistabilized triphenylphosphonium ylides with $\mathrm{N}$-sulfonyl imines. J. Am. Chem. Soc. 2010, 132, 5018-5020.

(19) Wittig, G.; Geissler, G. Zur Reaktionsweise Des Pentaphenyl-Phosphors Und Einiger Derivate. Justus Liebigs Ann. Chem. 1953, 580, 44-57.

(20) Maryanoff, B. E.; Reitz, A. B. The Wittig Olefination Reaction and Modifications Involving Phosphoryl-Stabilized Carbanions. Stereochemistry, Mechanism, and Selected Synthetic Aspects. Chem. Rev. 1989, 89, 863927.

(21) Julia, M.; Paris, J.-M. Syntheses a l'aide de Sulfones v(+)- Methode de Synthese Generale de Doubles Liaisons. Tetrahedron Lett. 1973, 14, 48334836.

(22) Blakemore, P. R. The Modified Julia Olefination: Alkene Synthesis via the Condensation of Metallated Heteroarylalkylsulfones with Carbonyl Compounds. J. Chem. Soc., Perkin Trans. 1 2002, 2563-2585.

(23) Chatterjee, B.; Bera, S.; Mondal, D. Julia-Kocienski Olefination: A Key Reaction for the Synthesis of Macrolides. Tetrahedron: Asymmetry 2014, 25, $1-55$.

(24) Vedejs, E.; Fang, H. W. An E-Selective 1,3-Diene Synthesis from Moderated Ylides and Aldehydes. J. Org. Chem. 1984, 49, 210-212.

(25) White, J. D.; Jensen, M. S. Synthesis of 1,3-Dienes of (E,Z) Configuration by a Three-Component Coupling Strategy. Tetrahedron 1995, 51, 5743-5756.

(26) Billard, F.; Robiette, R.; Pospíšil,J.Julia-Kocienski Reaction-Based 1,3Diene Synthesis: Aldehyde-Dependent (E,E/E, Z)-Selectivity. J. Org. Chem. 2012, 77, 6358-6364.

(27) Hubert, P.; Seibel, E.; Beemelmanns, C.; Campagne, J.-M.; Figueiredo, R. M. de. Stereoselective Construction of (E,Z)-1,3-Dienes and Its Application in Natural Product Synthesis. Adv. Synth. Catal. 2020, 362, 5532-5575. (28) McNulty, J.; McLeod, D.; Das, P.; Zepeda-Velázquez, C. Wittig Reactions of Trialkylphosphine-Derived Ylides: New Directions and Applications in Organic Synthesis. Phosphorus, Sulfur, and Silicon and the Related Elements 2015, 190, 619-632.

(29) Wang, G.; Mohan, S.; Negishi, E. Highly selective synthesis of conjugated dienoic and trienoic esters via alkyne elementometalation-Pd-catalyzed cross-coupling. Proc. Natl. Acad. Sci. USA 2011, 108, 11344-11349.

(30) Kurosawa, F.; Nakano, T.; Soeta, T.; Endo, K.; Ukaji, Y. (Z)-Selective enol triflation of $\alpha$-alkoxyacetoaldehydes: Application to synthesis of $(Z)$-allylic alcohols via cross-coupling reaction and $[1,2]$-Wittig rearrangement. $J$. Org. Chem. 2015, 80, 5696-5703.

(31) McAdam, C. A.; McLaughlin, M. G.; Cook, M.J. An alkyne hydrosilylation-Hiyama coupling approach to highly functionalised 1,3-dienes. Org. Chem. Front. 2015, 2, 510-514. 
(32) Hornillos, V.; Giannerini, M.; Vila, C.; Fañanás-Mastral, M.; Feringa, B.L. Direct catalytic cross-coupling of alkenyllithium compounds. Chem. Sci. 2015, 6, 1394-1398.

(33) Fiorito, D.; Folliet, S.; Liu, Y.; Mazet, C. A general nickel-catalyzed Kumada vinylation for the preparation of 2-substituted 1,3-dienes. ACS Catal. 2018, 8, 1392-1398.

(34) Scaringi, S.; Mazet, C. Kinetically Controlled Stereoselective Access to Branched 1,3-Dienes by Ru-Catalyzed Remote Conjugative Isomerization. ACS Catal. 2021, 11, 7970-7977.

(35) Wen, Z.-K.; Xu, Y.-H.; Loh, T.-P. Palladium(II)-catalyzed cross-coupling of simple alkenes with acrylates: A direct approach to 1,3-dienes through C-H activation. Chem. Sci. 2013, 4, 4520-4524.

(36) Liu, M.; Yang, P.; Karunananda, M.K.; Wang, Y.; Liu, P.; Engle, K.M. $\mathrm{C}$ (alkenyl)-H activation via six-membered palladacycles: Catalytic 1,3diene synthesis. J. Am. Chem. Soc. 2018, 140, 5805-5813.

(37) Horii, S.; Ishimaru, I.; Ukaji, Y.; Inomata, K. Stereoselective one-pot 1,4-elimination and the $[1,2]$-Wittig rearrangement of (E)- $\delta$-(arylmethoxy or 3-silyl-2-propynyloxy)-substituted allylic sulfones. Chem. Lett. 2011, 40, 521-523.

(38) Bauer, R.A.; Diblasi, C.M.; Tan, D.S. The tert-butylsulfinamide lynchpin in transition-metal-mediated multiscaffold library synthesis. Org. Lett. 2010, 12, 2084-2087.

(39) Dolan, M. A.; Dixon, A. D. C.; Chisholm, J. D.; Clark, D. A. Ruthenium dihydride complexes as enyne metathesis catalysts. Tetrahedron Lett. $\mathbf{2 0 1 8}$ 59, 4471-4474.

(40) Dang, H. T.; Nguyen, V. D.; Haug, G. C.; Vuong, N. T. H.; Arman, H. D.; Larionov, O. V. Z -Selective Dienylation Enables Stereodivergent Construction of Dienes and Unravels a Ligand-Driven Mechanistic Dichotomy. ACS Catal. 2021, 11, 1042-1052.

(41) Olivares, A. M.; Weix, D. J. Multimetallic Ni- and Pd-catalyzed CrossElectrophile Coupling to Form Highly Substituted 1,3-Dienes. J. Am. Chem. Soc. 2018, 140, 2446-2449.

(42) Pirnot, M. T.; Wang, Y.-M.; Buchwald, S. L. Copper Hydride Catalyzed Hydroamination of Alkenes and Alkynes. Angew. Chem., Int. Ed. 2016, 55, 48-57.

(43) Liu, R. Y.; Buchwald, S. L. CuH-Catalyzed Olefin Functionalization: From Hydroamination to Carbonyl Addition. Acc. Chem. Res. 2020, 53, 1229-1243.

(44) Li, C.; Shin, K. Y.; Liu, R.; Buchwald, S. L. Engaging Aldehydes in CuHCatalyzed Reductive Coupling Reactions: Stereoselective Allylation with Unactivated 1,3-Diene Pronucleophiles. Angew. Chem. Int. Ed. 2019, 58, 17074-17080.

(45) Li, C.; Liu, R. Y.; Jesikiewicz, L. T.; Yang, Y.; Liu, P.; Buchwald, S. L. $\mathrm{CuH}$-Catalyzed Enantioselective Ketone Allylation with 1,3-Dienes: Scope, Mechanism, and Applications. J. Am. Chem. Soc. 2019, 141, 5062-5070.

(45) Gribble, M. W.; Liu, R. Y.; Buchwald, S. L. Evidence for Simultaneous Dearomatization of Two Aromatic Rings under Mild Conditions in $\mathrm{Cu}(\mathrm{I})$ Catalyzed Direct Asymmetric Dearomatization of Pyridine. J. Am. Chem. Soc. 2020, 142, 11252-11269.

(46) Knippel, J. L.; Ye, Y.; Buchwald, S. L. Enantioselective C2-Allylation of Benzimidazoles Using 1,3-Diene Pronucleophiles. Org. Lett. 2021, 23, 2153-2157.

(47) Friis, S. D.; Pirnot, M. T.; Buchwald, S. L. Asymmetric Hydroarylation of Vinylarenes Using a Synergistic Combination of $\mathrm{CuH}$ and Pd Catalysis. J. Am. Chem. Soc. 2016, 138, 8372-8375.

(48) Schuppe, A. W.; Borrajo-Calleja, G. M.; Buchwald, S. L. Enantioselective Olefin Hydrocyanation without Cyanide. J. Am. Chem. Soc. 2019, 141, 18668-18672.

(49) Lu, Z.; Buchwald, S. L. Enantioselective Preparation of Arenes with $\beta$ Stereogenic Centers: Confronting the 1,1-Disubstituted Olefin Problem
Using $\mathrm{CuH} / \mathrm{Pd}$ Cooperative Catalysis. Angew. Chem. Int. Ed. 2020, 59, 16128-16132.

(50) Schuppe, A. W.; Knippel, J. L.; Borrajo-Calleja, G. M.; Buchwald, S. L. Enantioselective Hydroalkenylation of Olefins with Enol Sulfonates Enabled by Dual Copper Hydride and Palladium Catalysis. J. Am. Chem. Soc. 2021, 143, 5330-5335.

(51) Shi, S.-L.; Buchwald, S. L. Copper-catalysed selective hydroamination reactions of alkynes. Nat. Chem. 2015, 7, 38-44.

(52) Rao, S. A.; Periasamy, M. Hydrocupration of Alkynes: A Simple Synthesis of (E,E)-1,3-Dienes. J. Chem. Soc., Chem. Commun. 1987, 495-496.

(53) Uehling, M. R.; Suess, A. M.; Lalic, G. Copper-Catalyzed Hydroalkylation of Terminal Alkynes. J. Am. Chem. Soc. 2015, 137, 1424.

(54) Suess, A. M.; Uehling, M. R.; Kaminsky, W.; Lalic, G. Mechanism of Copper-Catalyzed Hydroalkylation of Alkynes: An Unexpected Role of Dinuclear Copper Complexes. J. Am. Chem. Soc. 2015, 137, 7747.

(55) Kortman, G. D.; Hull, K. L. Copper-Catalyzed Hydroarylation of Internal Alkynes: Highly Regio- and Diastereoselective Synthesis of 1,1-Diaryl, Trisubstituted Olefins. ACS Catal. 2017, 7, 6220-6224.

(56) Cheng, L.-J.; Mankad, N. P. Cu-Catalyzed Hydrocarbonylative C-C Coupling of Terminal Alkynes with Alkyl Iodides. J. Am. Chem. Soc. 2017, 139, 10200-10203.

(57) Hazra, A.; Chen, J.; Lalic, G. Stereospecific Synthesis of E-Alkenes through Anti-Markovnikov Hydroalkylation of Terminal Alkynes. J. Am. Chem. Soc. 2019, 141, 12464-12469.

(58) Gao, D.-W.; Gao, Y.; Shao, H.; Qiao, T.-Z.; Wang, X.; Sanchez, B. B.; Chen, J. S.; Liu, P.; Engle, K. M. Cascade CuH-catalysed conversion of alkynes into enantioenriched 1,1-disubstituted products. Nat. Catal. 2020, 3, 23-29.

(59) Hazra, A.; Kephart, J. A.; Velian, A.; Lalic G. Hydroalkylation of Alkynes: Functionalization of the Alkenyl Copper Intermediate through Single Electron Transfer Chemistry. J. Am. Chem. Soc. 2021, 143, 7903-7908.

(60) Garcïa-Melchor, M.; Braga, A. A. C.; Lledós, A.; Ujaque, G.; Maseras, F. Computational Perspective on Pd-Catalyzed C-C Cross-coupling Reaction Mechanisms. Acc. Chem. Res. 2013, 46, 2626-2634.

(61) The use of a chiral ligand is not necessary, however rac-L1 is not commercially available, therefore, $(S)$-L1 was employed. Other racemic or achiral ligands were less effective in this transformation, see Supporting Information for details.

(62) Niljianskul, N.; Zhu, S.; Buchwald, S. L. Enantioselective Synthesis of a-Aminosilanes by Copper-Catalyzed Hydroamination of Vinylsilanes. Angew. Chem. Int. Ed. 2015, 54, 1638-1641.

(63) White, J. M.; Clark, C. I. Stereoelectronic Effects of the Group 4 Metal Substituents in Organic Chemistry. In Topics in Stereochemistry, vol. 22; John Wiley \& Sons, 2009; pp 137-200. 